\title{
Ontario children have outgrown the Broselow tape
}

\author{
William Ken Milne, MD, CCFP-EM, FCFP*; Abeer Yasin ${ }^{\dagger}$; Janine Knight, BHSc ${ }^{\ddagger}$; \\ Daniel Noel, MD, CCFP'; Richard Lubell, $\mathrm{MD}^{\dagger}$; Guido Filler, $\mathrm{MD}, \mathrm{PhD}^{\dagger}$
}

\section{ABSTRACT}

Objective: The Broselow Pediatric Emergency Tape (Armstrong Medical Industries, Inc., Lincolnshire, IL) (BT) is a wellestablished length-based tool for estimation of body weight for children during resuscitation. In view of pandemic childhood obesity, the BT may no longer accurately estimate weight. We therefore studied the BT in children from Ontario in a large recent patient cohort.

Methods: Actual height and weight were obtained from an urban and a rural setting. Children were prospectively recruited between April 2007 and July 2008 from the emergency department and outpatient clinics at the London Health Science Centre. Rural children from junior kindergarten to grade 4 were also recruited in the spring of 2008 from the Avon Maitland District School Board. Data for preschool children were obtained from three daycare centres and the electronic medical record from the Maitland Valley Medical Centre. The predicted weight from the BT was compared to the actual weight using Spearman rank correlation; agreement and percent error (PE) were also calculated.

Results: A total of 6,361 children ( $46.2 \%$ female) were included in the study. The median age was 3.9 years (interquartile range [IQR] 1.56-7.67 years), weight was $17.2 \mathrm{~kg}$ (IOR 11.6$25.4 \mathrm{~kg}$ ), and height was $103.5 \mathrm{~cm}$ (IOR 82-124.4 cm). Although the BT weight estimate correlated with the actual weight $(r=0.95577, p<0.0001)$, the $\mathrm{BT}$ underestimated the actual weight by $1.62 \mathrm{~kg}(7.1 \% \pm 16.9 \% \mathrm{SD}, 95 \% \mathrm{Cl}-26.0$ 40.2). The BT had an $\geq 10 \%$ PE $43.7 \%$ of the time.

Conclusions: Although the BT remains an effective method for estimating pediatric weight, it was not accurate and tended to underestimate the weight of Ontario children. Until more accurate measurement tools for emergency departments are developed, physicians should be aware of this discrepancy.

\section{RÉSUMÉ}

Objectif: L'échelle de Broselow (Broselow Tape [BT]) est un outil reconnu qui sert à estimer le poids d'un enfant en fonction de sa taille lors d'une réanimation. Compte tenu de la pandémie d'obésité infantile, l'échelle de Broselow pourrait ne plus estimer le poids de façon précise. Nous avons donc étudié l'échelle de Broselow chez l'enfant, en Ontario, dans une importante cohorte récente de patients.

Méthodes: Les tailles et poids actuels ont été recueillis dans une zone urbaine et une zone rurale. Les enfants ont été recrutés de façon prospective entre avril 2007 et juillet 2008, à partir du service d'urgence et des cliniques de consultation externe du London Health Sciences Centre. Au printemps 2008, des enfants de régions rurales fréquentant les classes de prématernelle à la $4^{\mathrm{e}}$ année de la Avon Maitland District School Board ont également été recrutés. Les données des enfants d'âge préscolaire ont été obtenues de trois garderies et à partir des dossiers médicaux électroniques du Maitland Valley Medical Centre. Le poids estimé selon l'échelle de Broselow a été comparé au poids réel au moyen de la corrélation de rangs de Spearman; la concordance et le pourcentage $d^{\prime}$ erreur (PE) ont aussi été calculés.

Résultats: Un total de 6,361 enfants (46,2\% de filles) ont été inclus dans l'étude. L'âge médian était de 3,9 ans (écart interquartile [EIQ] 1,56 à 7,67 ans), le poids médian de 17,2 kg (EIO de 11,6 à 25,4 kg), et la taille médiane de 103,5 cm (EIQ de 82 à 124,4 cm). Bien que les poids estimés à l'aide de l'échelle de Broselow aient été corrélés avec les poids réels ( $r$ $=0,95577, p<0,0001)$, l'échelle de Broselow a sous-estimé le poids réel de 1,62 $\mathrm{kg}(7,1 \% \pm 16,9 \%$ écart-type, IC à $95 \%$ : 26,0 à 40,2). L'échelle de Broselow avait un $\geq 10 \% \operatorname{PE~} 43,7 \%$ du temps.

Conclusions: Bien que l'échelle de Broselow reste une méthode efficace d'estimation du poids en pédiatrie, elle ne s'est pas montrée exacte et tend à sous-estimer le poids des enfants en Ontario. Tant que I'on n'aura pas développé d'outil de mesure plus précis pour les services d'urgence, les médecins doivent être conscients de cette divergence.

Keywords: Broselow Pediatric Emergency Tape, Canadian, obesity, pediatrics, resuscitation

From the *Division of Emergency Medicine, University of Western Ontario, London, ON; †Department of Pediatrics, University of Western Ontario, London, ON; łFaculty of Medicine, University of Ottawa, Ottawa, ON; and §Maitland Valley Medical Centre, Goderich, ON.

Correspondence to: Dr. Guido Filler, Department of Paediatrics, University of Western Ontario, 800 Commissioners Road East, London, ON N6A 5W9; guido.filler@Ihsc.on.ca

This article has been peer reviewed.

(c) Canadian Association of Emergency Physicians 
A rapid and accurate estimate of a child's weight can be of critical importance for pediatric emergencies and resuscitation. This is because drug dosages, defibrillation energy (joules), and endotracheal (ET) tube size are based on the child's weight. ${ }^{1,2}$ The Broselow Pediatric Emergency Tape (BT) was developed in the late 1980s as a tool to determine a child's weight based on length and has become the standard method in many emergency departments (EDs). ${ }^{3,4}$

The worldwide childhood obesity epidemic, however, gives rise to the question of whether the BT is still accurate. In 2002, the Broselow 2002A tape was introduced, which accommodated the newer National Health and Nutrition Examination Survey (NHANES) III reference intervals. In 2000, the World Health Organization referred to obesity as a global pandemic. 5 Childhood obesity has been referred to as a new chronic disease that overshadows all other pediatric diseases. ${ }^{5,6}$ Canadian research has shown that the rates of obesity and overweight children have more than doubled in recent decades. More than one in three Canadian children are now considered overweight or obese..$^{7-12}$

In light of the high obesity rates, recent studies on the BT have questioned whether this method still accurately estimates the weight of children. ${ }^{13-16}$ As the BT has not been revalidated in light of the childhood obesity epidemic, we studied a representative cohort to address the question of whether the BT accurately estimates the weight of children in Ontario, the most populous province of Canada.

\section{METHODS}

\section{Design and Setting}

There were two main settings for obtaining the height and weight of Canadian children. The first setting was an urban tertiary care centre. Patients were prospectively recruited from the ED and various outpatient clinics between April 2007 and July 2008. Anthropometric measurements were obtained as clinical routine. Height was measured by stadiometers: the infant stadiometer from Perspection Enterprises (Portage, MI) or the Seca 242 mechanical personal measuring rod (Hanover, MD). Weight was measured using a high-precision industrial scale at both institutions: Scale-Tronix scales (Wheaton, IL) 6002 for wheelchair patients, 4802 for infants, and 5002 otherwise. The second setting was rural children living in southwestern Ontario. School-age children attending the Avon Maitland District School Board (AMDSB) from junior kindergarten to grade 4 were prospectively measured wearing light-fitting clothes and no shoes in the spring of 2008. Height and weight were obtained using a standard physician scale. For the BT, we used the 2002A tape rather than the older 1999 tape. The 2002A tape incorporates the NHANES III reference intervals that we also used for the statistical comparison.

Data on preschool children were also prospectively collected in the spring of 2008 from three rural daycare centres. Additional preschool children data were retrospectively obtained from a search of the Maitland Valley Medical Centre (MVMC) Family Health Team electronic medical record in December 2008. The most recent outpatient visit with a documented height and weight were extracted from the database. Children were weighed in light-fitting clothes with no shoes. Infants were undressed for their weight, and their length was determined using a standard measuring tape.

Body mass index (BMI) was calculated from the ratio of weight (kilograms) and the square of the height (centimeters). Age-independent BMI $z$ scores were calculated using the methodology provided by the Centers for Disease Control and Prevention website, with age- and gender-matched controls taken from the US National Center for Health Statistics. Due to the lack of reference intervals for BMI $z$ scores for children younger than 2 years of age, we instead calculated ageindependent weight-for-height $z$ scores. The most recent NHANES III database (1999-2002) for all patients ${ }^{17}$ was used as a reference for the calculations of $z$ scores. Finally, we calculated the weight and BMI $z$ score from the rural data set (age $>24$ months only because of the lack of availability of BMI reference intervals) and compared these to age- and gendermatched controls from the urban group.

\section{Statistical Analysis}

Statistical analysis was performed with GraphPad Prism version 4.02 for Windows (GraphPad Software, San Diego, CA). Continuous data were assessed for normal distribution using the D'Agostini-Pearson omnibus test. Mean and standard deviation were reported for normally distributed data; otherwise, median and 
interquartile ranges (IQRs; 25th and 75th percentiles) were reported. Simple descriptive tests were employed using appropriate parametric tests for normally distributed data and nonparametric tests otherwise. Where data were not normally distributed, the predicted weight from the BT was analyzed against the actual weight using the nonparametric Spearman rank correlation analysis. Comparison between groups (rural and urban) was performed using the nonparametric Mann-Whitney test. The nonparametric Wilcoxon signed rank test was used to check for significant difference from the hypothetical mean of zero between the urban and rural groups. A $p$ value $<$ 0.05 was considered statistically significant.

\section{Ethics}

Ethics approval for this study was obtained from the University of Western Ontario (REB number \#15193E), and from AMDSB, South Huron Hospital Medical Advisory Committee, and MVMC Family Health Team.

\section{RESULTS}

There were 5,093 subjects from the urban data set and 1,268 from the rural group. A Mann-Whitney test for the comparison between the two data sets showed significant differences in age, with an older rural cohort, leading to significant differences in height, actual weight, and BT-estimated weight (Table 1). However, there was no difference between the percent differences of the actual weight and the BT-estimated weight for the two groups (Wilcoxon signed rank test, $p=1.0000$ ). To further study whether the two groups were different, we calculated weight $z$ score and BMI $z$ score in a matched pair subgroup of children $(n=388)$ aged 24 to 143 months. Age distribution was identical. There was no significant difference in the weight $z$ score: rural group $z$ score +0.2558 (IQR $-0.4092-$ 0.8727 ); urban group $z$ score +0.3504 (IQR $-0.3822-$ 1.138). There was a slight difference in the BMI $z$ score, opposite to what was expected, with the urban BMI $z$ score of +0.4134 (IQR $-0.3578-1.053$ ) slightly higher than the rural BMI $z$ score of +0.2558 (IQR $-0.4092-0.8727)$. As such, the rural group certainly did not confound the results.

This permitted the urban and rural data to be pooled for analysis of 6,361 children. A total of 6,361 children (46.2\% female) were included in the study. The median age was 3.9 years (IQR 1.56-7.67 years), weight was $17.2 \mathrm{~kg}$ (IQR 11.6-25.4 kg), and height was $103.5 \mathrm{~cm}$ (IQR 82-124.4 cm) (Table 2).

The analysis of weight for height revealed that a larger proportion of patients had weight for height above the 97th percentile than a weight for height below the $3 \mathrm{rd}$ percentile (Figure 1). The findings are better illustrated in Figure 2, which shows the relationship between the height and the weight-forheight $z$ score together with the reference interval and the regression line that was significantly above zero. The slope of the linear regression line was -0.003440 \pm 0.001174 , with a $y$-intercept when $x=0.0$ of 0.8097 \pm 0.1092 and an $x$-intercept when $y=0.0$ of $235.4 \mathrm{~cm}$. The $r$ value was low at 0.043 but was significantly nonzero $(p=0.0034)$, suggesting that younger children were slightly more obese than older children.

The Bland-Altman analysis of actual weight versus BT-estimated weight showed a bias of $1.621 \mathrm{~kg}$. The standard deviation of bias was $4.76 \mathrm{~kg}(95 \% \mathrm{CI}-7.71-$ 10.95), as shown in Figure 3. Although there was good correlation between the BT weight estimate and the actual weight $(r=0.95577, p<0.0001)$, there was a significant bias of $7.10 \%$, with a standard deviation of $16.88 \%$ (95\% CI -25.98-40.19). The BT-estimated weights were $56.3 \%$ within $10 \%$ error, $84.5 \%$ within $20 \%$ error, and $94.1 \%$ within $30 \%$ error (Table 3 ). A percent error of $\geq 10 \%$ was considered significant.

\section{DISCUSSION}

It is often impossible to use traditional methods to determine a pediatric patient's weight during a crisis

\begin{tabular}{|c|c|c|c|c|}
\hline Variable & $\begin{array}{c}\text { Rural } \\
(n=1,268)\end{array}$ & $\begin{array}{c}\text { Urban } \\
(n=5,093)\end{array}$ & $\begin{array}{l}\text { Mann-Whitney } \\
p \text { value }\end{array}$ & $\begin{array}{c}\text { Medians significantly } \\
\text { different? }\end{array}$ \\
\hline Age (yr) & 6.95 & 3.78 & $<0.0001$ & Yes \\
\hline Weight (kg) & 20.25 & 16.50 & $<0.0001$ & Yes \\
\hline Height (cm) & 113.70 & 100.90 & $<0.0001$ & Yes \\
\hline Broselow tape $(\mathrm{kg})$ & 19.00 & 15.00 & $<0.0001$ & Yes \\
\hline
\end{tabular}




\begin{tabular}{|c|c|c|c|c|c|c|}
\hline Variable & Median & $\begin{array}{c}\text { 25th } \\
\text { percentile }\end{array}$ & $\begin{array}{c}\text { 75th } \\
\text { percentile }\end{array}$ & Minimum & Maximum & $\begin{array}{c}\text { Normality test } \\
p \text { value }\end{array}$ \\
\hline Age (yr & 3.93 & 1.56 & 7.67 & 0.01 & 18.04 & $<0.0001$ \\
\hline Weight (kg) & 17.20 & 11.60 & 25.40 & 2.30 & 97.50 & $<0.0001$ \\
\hline Height (cm) & 103.50 & 82.00 & 124.40 & 46.00 & 146.50 & $<0.0001$ \\
\hline $\begin{array}{l}\text { Broselow tape } \\
(\mathrm{kg})\end{array}$ & 16.00 & 11.00 & 24.00 & 3.000 & 36.00 & $<0.0001$ \\
\hline
\end{tabular}

situation. Accurate weights are important for calculating drug dosing, defibrillation energy (joules), and ET tube size. ${ }^{1,2}$ A variety of methods have been developed over the years to rapidly estimate a child's weight. The BT was developed over 30 years ago and was a great advance in standardizing pediatric resuscitation. ${ }^{3,4} \mathrm{It}$ reduced the amount of memorization, estimation, and calculations during critical illnesses and trauma. However, the serious trend of childhood obesity has called into question the validity of a length-based technology. ${ }^{5-12}$

Our study demonstrated that the BT was biased toward underestimating the actual weight by $7.1 \%$ on a large cohort of children from Ontario. It has an error $\geq 10 \%$ for more than two of five cases $(43.7 \%)$.

This agrees with a number of studies showing that the BT is not accurate and tends to underestimate the weight of children in a variety of populations. ${ }^{2,13,16,18}$ The current study agrees with a prospective study done in 499 Canadian children attending their pediatrician's office. ${ }^{19}$ It also agrees with data looking at Aboriginal children in Canada. ${ }^{16}$ Overall, $94.1 \%$ of data were within 30\% error, however, which would form a reasonable agreement for most estimated laboratory parameters. The spread of the confidence interval

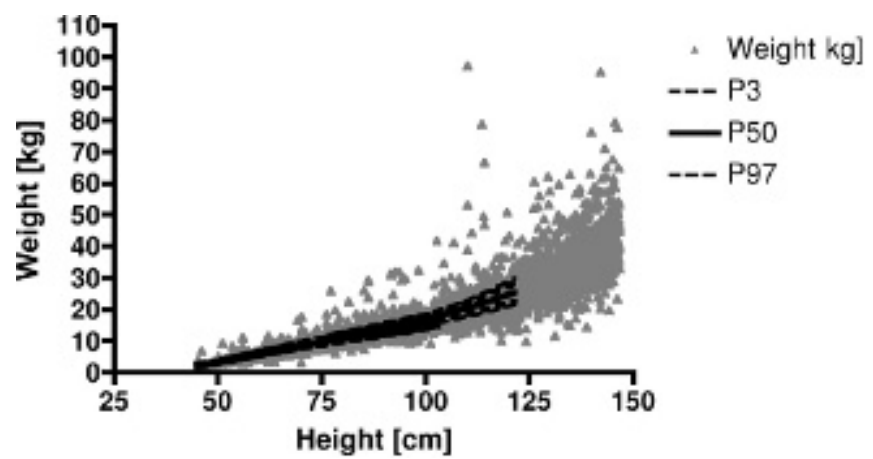

Figure 1. The relationship between height and weight in all patients with the appropriate weight-for-height reference intervals for children under $122 \mathrm{~cm}$ (National Center for Health Statistics $\left.{ }^{17}\right)$. There were significantly more children above the 97 th percentile than below the 3rd percentile.
(7.1\% with a standard deviation of $16.8 \%$ ) does not land above zero and therefore does not invalidate the results of the BT.

A strength of this study was the variety of settings where children's measurement data were collected. These settings included a tertiary care hospital ED, outpatient clinics, elementary schools for school children, and daycare centres and primary care provider offices for preschool children. It also included a mix of both urban and rural children. Over 6,000 children were measured, which represents the largest study ever performed to validate the BT in Canadian children. The size and variety of settings make the results of this study very robust.

Other related studies completed on populations in India $^{14}$ and Korea ${ }^{15}$ have shown that the BT still performs well. These contradicting data probably reflect the balance between energy intake and expenditure in different populations and their rate of childhood obesity.

The significant bias found in our research could have serious implications for the treatment of critically ill or injured Canadian children. Resuscitation medications are weight based for pediatric patients. It is known that one of the most comment errors in pediatric emergencies is incorrect dosing due to inaccurate weight estimations. ${ }^{20}$

The Pediatric Advanced Life Support (PALS) guidelines recommend a dose of $0.01 \mathrm{mg} / \mathrm{kg}$ of adrenalin when indicated by intravenous or intraosseous infusion. ${ }^{1}$ Our study showed that children from Ontario are at risk of underdosing, which may adversely affect the success of resuscitation of these children. Another life-saving treatment used during resuscitation is defibrillation. The PALS guidelines recommend up to three shocks of increasing intensity $(2,2-4$, and $4 \mathrm{~J} / \mathrm{kg}) .{ }^{1}$ This study demonstrates that for close to half of the children, there would more than $10 \%$ error in calculating the amount of joules required during ventricular fibrillation or pulseless ventricular 


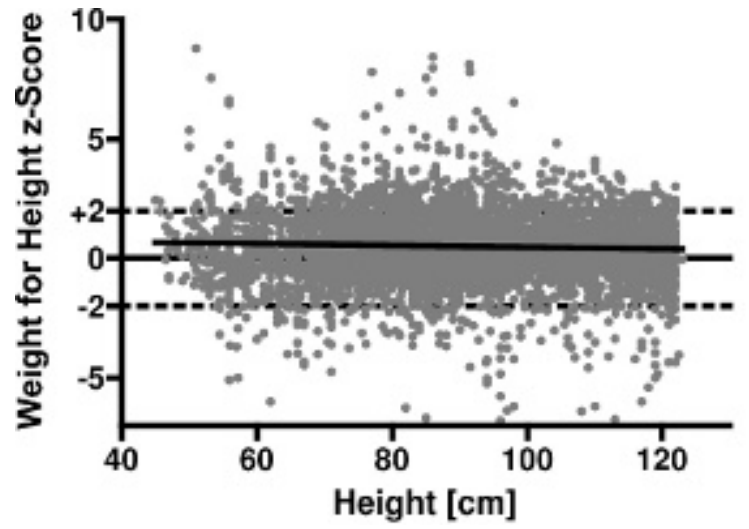

- Weight for Height z-score
Figure 2. The relationship between the height (centimeters) and the weight-for-height $z$ score in all children under $121 \mathrm{~cm}$. The slope of the regression line was negative and significantly nonzero, suggesting that the degree of overweight was actually slightly higher in the younger children than in the older children. tachycardia. The American Heart Association acknowledges that the safe limits for defibrillation are unknown because the evidence is poor; however, we should try to eliminate all potential for error if possible. ${ }^{1}$

Another critical treatment used in pediatric resuscitation is assisted ventilation with ET tubes. The size of the ET tube is based on BT-estimated weight. If the weight is underestimated, it could result in an undersized ET tube being used. Undersized ET tubes can lead to air leaks, inadequate ventilation, and, ultimately, insufficient oxygenation. ${ }^{2}$ Rather than using a length-based system, Yamamoto and colleagues investigated the addition of a body habitus modifier to the BT. ${ }^{21}$ Their study found improved weight estimate accuracy especially for children over the age of 3 years.

Our study has several limitations. We did not have the age in months in all children of the rural group. Therefore, we could not compare the age-independent weight and BMI $z$ scores in both groups and cannot

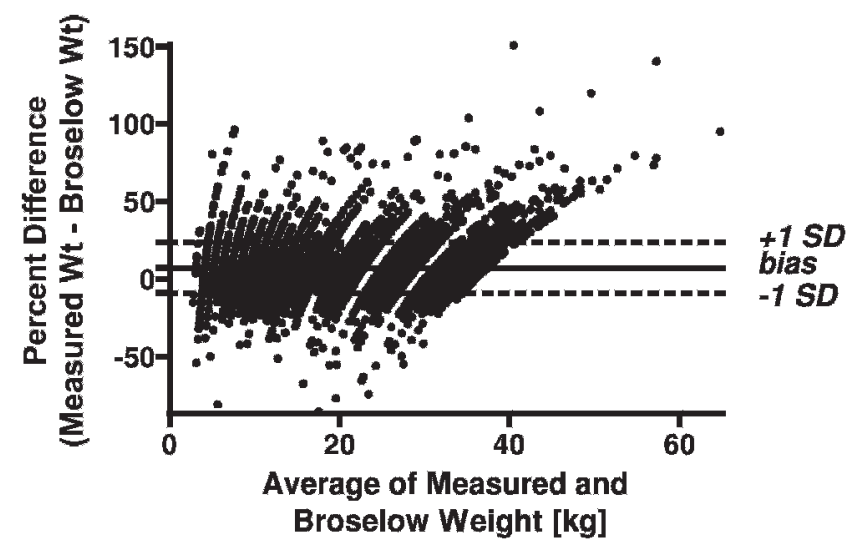

Figure 3. Bland-Altman graph of absolute differences between actual weight and Broselow tape-estimated weight $(N=6,361)$. comment whether rural children would have a higher prevalence of obesity. Weight $z$ scores in the matched pair subgroup analysis did not differ. Moreover, the differences between the actual weight and the BT weight did not differ between both groups, which prompted us to combine them. Another limitation would be the assumption that our sample population has the same weight as the population of children requiring resuscitation presenting to EDs.

The overall sample size is larger than that of the NHANES data set $(n=5,750$ children and adolescents 0 to 19 years of age; 2,779 female $^{17}$ ). Comparison of the ED patients and population data from London revealed no differences in BMI $z$ scores (unpublished data). We also cannot comment on the general population of Canadian children. The characteristics are not evenly distributed across the country, with rates ranging from $22 \%$ in Alberta to $36 \%$ in Newfoundland, based on 2004 data.22 Usually, rural areas have a higher rate of obesity than urban areas. The slightly lower BMI $z$ score in the rural setting may be explained by the Mennonite population in the Exeter, Ontario, region, a population that is usually leaner than the average Canadian population. Nonetheless, despite this limitation and a potential overestimation of weight in our sample, the large number of subjects and the consecutive recruitment of

\begin{tabular}{|lrc|}
\hline \multicolumn{2}{|l|}{ Table 3. Percent error $(\boldsymbol{N}=\mathbf{6 , 3 6 1})$} \\
\hline Precent error & $n$ & $\%$ \\
\hline Within $10 \%$ error & 3,579 & 56.3 \\
Within $20 \%$ error & 5,378 & 84.5 \\
Within 30\% error & 5,985 & 94.1 \\
\hline
\end{tabular}


over $80 \%$ of all possible patients make this error negligible. ${ }^{23}$

Instead of estimating pediatric weight, technology should be developed to safely and accurately determine a child's actual weight. Along with computer-assisted algorithms, emergency physicians could be provided with correct drug dosage, joules, and ET tube size during pediatric resuscitation. This would provide every child with standardized treatment, thereby minimizing one source of error during life-threatening illness or trauma.

\section{CONCLUSION}

Although the BT remains an effective method for estimating pediatric weight, it was not accurate and tended to underestimate the weight of Ontario children. This information should be considered when using this tool for pediatric resuscitation.

Competing interests: None declared.

\section{REFERENCES}

1. ECC Committee, Subcommittees and Task Forces of the American Heart Association. 2005 American Heart Association guidelines for cardiopulmonary resuscitation and emergency cardiovascular care. Circulation 2005;112 (24 Suppl):167-88.

2. Hofer CK, Ganter M, Tucci M, et al. How reliable is length-based determination of body weight and tracheal tube size in the paediatric age group? The Broselow tape reconsidered. Br 7 Anaesth 2002;88:283-5, doi:10.1093/bja/ 88.2.283.

3. Lubitz DS, Seidel JS, Chameides L, et al. A rapid method for estimating weight and resuscitation drug dosages from length in the pediatric age group. Ann Emerg Med 1988;17: 576-81, doi:10.1016/S0196-0644(88)80396-2.

4. Luten RC, Wears RL, Broselow J, et al. Length-based endotracheal tube and emergency equipment in pediatrics [published erratum appears in Ann Emerg Med 1993;22:155]. Ann Emerg Med 1992;21:900-4, doi:10.1016/S0196-0644 (05)82924-5.

5. World Health Organization, Obesity: preventing and managing the global epidemic. Geneva: World Health Organization; 2000, Technical Report Series \#894.

6. Sokol RJ. The chronic disease of childhood obesity: the sleeping giant has awakened. I Pediatr 2000;136:711-3, doi: $10.1067 / \mathrm{mpd} .2000 .107787$.

7. Tremblay MS, Katzmarzyk PT, Willms JD. Temporal trends in overweight and obesity in Canada, 1981-1996. Int 7 Obes Relat Metab Disord 2002;26:538-43.
8. Canning PM, Courage ML, Frizzell LM. Prevalence of overweight and obesity in a provincial population of Canadian preschool children. CMA7 2004;171:240-2, doi:10.1503/cmaj.1040075.

9. He M, Sutton J. Using routine growth monitoring data in tracking overweight prevalence in young children. Can 7 Public Health 2004;95:419-23.

10. Veugelers PJ, Fitzgerald AL. Prevalence of and risk factors for childhood overweight and obesity. CMA7 2005;173:60713, doi:10.1503/cmaj.050445.

11. Tjepkema M. Measured obesity. Adult obesity in Canada: measured beight and weight. Ottawa: Statistics Canada; Statistics Canada Cat, No. 82-620-MWE2005001.

12. He M, Beynon C. Prevalence of overweight and obesity in school-aged children. Can 7 Diet Pract Res 2006;67:125-9, doi:10.3148/67.3.2006.125.

13. Black K, Barnett P, Wolfe R, et al. Are methods used to estimate weight in children accurate? Emerg Med (Fremantle) 2002;14:160-5, doi:10.1046/j.1442-2026.2002.00311.x.

14. Varghese A, Vasudevan VK, Lewin S, et al. Do length-based BT, APLS, Argall and Nelson's formulae accurately estimate weight of Indian children? Indian Pediatr 2006;43:889-94.

15. Jang HY, Shin SD, Kwak YH. Can the Broselow tape be used to estimate weight and endotracheal tube size in Korean children? Acad Emerg Med 2007;14:489-91.

16. Anstett D, Bawden J, Moylette E, et al. Does the Broselow Tape accurately estimate the weight of healthy Irish children? Presented at the Canadian Association of Emergency Physician Annual Meeting; 2009 June; Calgary, $\mathrm{AB}$.

17. National Center for Health Statistics. 2000 CDC growth charts: United States. Available at: http://www.cdc.gov/ growthcharts/ (accessed July 29, 2006).

18. Theron L, Adams A, Jansen K, et al. Emergency weight estimation in Pacific Island and Maori children who are large-for-age. Emerg Med Australas 2005;17:238-43, doi:10.1111/j.1742-6723.2005.00729.x.

19. Knight J, Lubell R, Milne WK. Does the Broselow Tape accurately estimate the weight of Canadian children? Presented at the Canadian Association of Emergency Physician Annual Meeting; 2008 June; Ottawa, ON.

20. Selbst SM, Fein JA, Osterhoudt K, et al. Medication errors in a pediatric emergency department. Pediatr Emerg Care 1999;15:1-4, doi:10.1097/00006565-199902000-00001.

21. Yamamoto LG, Inaba AS, Young LL, et al. Improving length-based weight estimates by adding a body habitus (obesity) icon. Am 7 Emerg Med 2009;27:810-5, doi:10.1016/ j.ajem.2008.06.023.

22. Improving the health of Canadians: prompting healthy weights. Canadian Population Health Initiative. Canadian Institute for Health Information. 2006. Ottawa, Canada. Available at: http:// secure.cihi.ca/cihiweb/products/healthyweights06_e.pdf (accessed March 26, 2011).

23. Filler G, Yasin A, Kesarwani P, et al. Big mother or small baby: which predicts hypertension? 7 Clin Hypertens. Available at: http://onlinelibrary.wiley.com/doi/10.1111/j.17517176.2010.00366.x/pdf (accessed August 20, 2010). 